\title{
Seronegative Myasthenia Gravis and a Biermer's Anemia: A Rare Association
}

\section{Boundia Djiba, Baïdy Sy Kane, Awa Cheikh Ndao, Michel Assane Ndour, Nafissatou Diagne, Atoumane Faye, Mohamed Dieng, Maïmouna Sow, Abdoulaye Pouye}

Department of Internal Medicine, Center Hospital Aristide Le Dantec, Dakar, Senegal

Email:boundiadjiba@yahoo.fr

How to cite this paper: Djiba, B., Kane, B.S., Ndao, A.C., Ndour, M.A., Diagne, N., Faye, A., Dieng, M., Sow, M. and Pouye, A. (2017) Seronegative Myasthenia Gravis and a Biermer's Anemia: A Rare Association. Open Journal of Internal Medicine, 7, 160-164. https://doi.org/10.4236/ojim.2017.74017

Received: November 3, 2017

Accepted: December 2, 2017

Published: December 5, 2017

Copyright $\odot 2017$ by authors and Scientific Research Publishing Inc. This work is licensed under the Creative Commons Attribution International License (CC BY 4.0).

http://creativecommons.org/licenses/by/4.0/

(c) (i) Open Access

\begin{abstract}
We report a rare association of seronegative myasthenia gravis and a Biermer's anemia (or pernicious anemia). A Senegalese patient of 31 years has been followed for a vitamin B12 deficiency anemia, 12 months before his hospitalization in our department. She has been admitted for an intense and invalidating fatigability in spite of the correction of anemia, associated to a right ptosis. This clinical picture has electively been improved to the prostigmine test. The electromyography had revealed a compatible decrement with a diagnosis of myasthenia. The positivity of the antibodies anti gastric parietal cells and the twice negativity of the antibody against acetylcholine receptor (AChR) and muscle-specific kinase (MuSK) had permitted to deduct a diagnosis of seronegative myasthenia and Biermer's anemia. The evolution was favorable under substitutive B12 vitamin therapy associated to corticotherapy and azathioprine. We insist on the research and the early treatment of a myasthenia, in a context of Biermer's anemia, before suggestive clinical signs in spite of the negativity of the anti-Rach antibodies and anti-Musk.
\end{abstract}

\section{Keywords}

Myasthenia Gravis, Pernicious Anemia, Seronegative

\section{Introduction}

The Biermer's anemia is a gastritis auto-immune atrophic characterized by the absence of gastric intrinsic factor secretion caused by a malabsorption of the B12 vitamin at the ileal level [1].

Myasthenia gravis is an auto-immune illness affecting the neuromuscular junction, usually associated to the presence of antibodies against acetylcholine receptor (AChR) and muscle-specific kinase (MuSK). 
In $20 \%$ of the cases, these antibodies are not however detectable, the myasthenia gravis is said negative [2].

The Myasthenia gravis association and Biermer's anemia is rare. We report the first Senegalese observation of an association of negative Myasthenia and Biermer's anemia.

\section{Observation}

This was about a patient of 31 years, accountant by trade who has been followed 12 months before her admission in our department for a megaloblastic anemia labeled Biermer's anemia under B12 vitamin therapy. She was hospitalized in our institution on February $05^{\text {th }}, 2015$ for an intense and invalidating fatigability in the effort so far attributed to anemia. To the questioning, she reported a generalized fatigability associated to a tendency to the closing of her right eye especially occurring at the end of the day.

Her general state was maintained, the mucous membranes were colored, and the admission constants were blood pressure $120 / 70 \mathrm{mmHg}$, cardiac frequency was 84 beatings per minute, respiratory frequency 18 cycles per minute, temperature $37.2^{\circ} \mathrm{C}$.

The admission exam revealed a palmoplantar melanoderma associated to a unilateral ptosis and a difficulty to horizontally maintain her arms for a duration over 30 seconds. The rest of the clinic examination was normal. The prostigmine test has been done right after with a significant improvement of the clinical symptomatology.

At the paraclinical examination the hemogram shows a hemoglobin level of $12 \mathrm{~g} / \mathrm{dl}$ (normal < $11 \mathrm{~g} / \mathrm{dl}$ ) normochromic, normocytic, the level of platelets of $369,000 / \mathrm{mm}^{3}$ (normal: 150,000 - 450,000) and the leukocytes level of 8140 cells $/ \mathrm{mm}^{3}$ (normal: 4000 - 10,000). There was no inflammatory syndrome with a sedimentation rate at the first hour to $25 \mathrm{~mm}$ (normal $<15 \mathrm{~mm}$ ) and a C-reactive protein of $5 \mathrm{mg} / \mathrm{l}$ (normal $<6 \mathrm{mg} / \mathrm{l}$ ). The electrophoresis of the serum proteins was without particularities, the ferritinemy was $50.97 \mathrm{ng} / \mathrm{ml}$ (normal: 12 - $150 \mathrm{ng} / \mathrm{ml}$ ). Elsewhere the dosage of the TSH us showed a rate of $1.47 \mathrm{mUI} / \mathrm{L}$ (normal between 0.27 and 4.2), the antibodies against-ENA, against-CCP2 and anti-TPO test was negative. The antibody against-parietal cells were negative and the antibody against intrinsic factors test was positive. The dosage of the auto-antibodies against Musk was 0.03 (normal lower to 0.05 ) and the dosage of the antibodies against AChR was twice lower than 0.20 UI. The duodenal-gastro-oesophageal fibroscopy revealed an atrophic gastritis of the fund us and the histology revealed an intestinal metaplasia. The electromyography identified a decrement of $5.5 \%$ on the pick 5 and $17,1 \%$ on the pick 9 at the orbicular eyelid, a decrement of $30 \%$ on the picks 1 and 2 at the abductor thumb (Figure 1).

This aspect was compatible with a myasthenia. The thoracic tomodensitometry was unremarkable. The diagnosis of a seronegative myasthenia gravis has been put association of a Biermer anemia. 


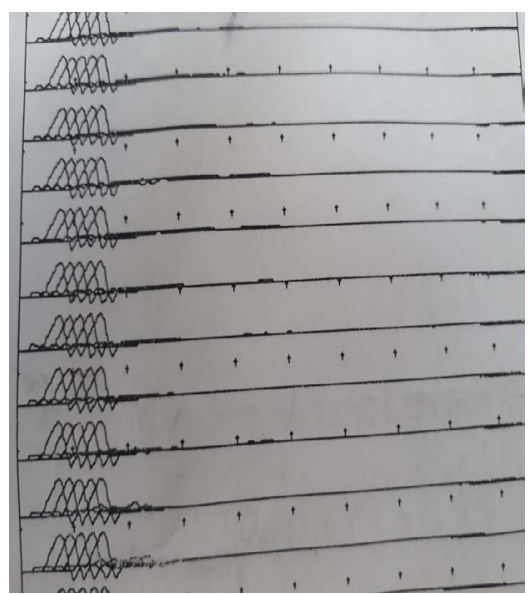

(a)

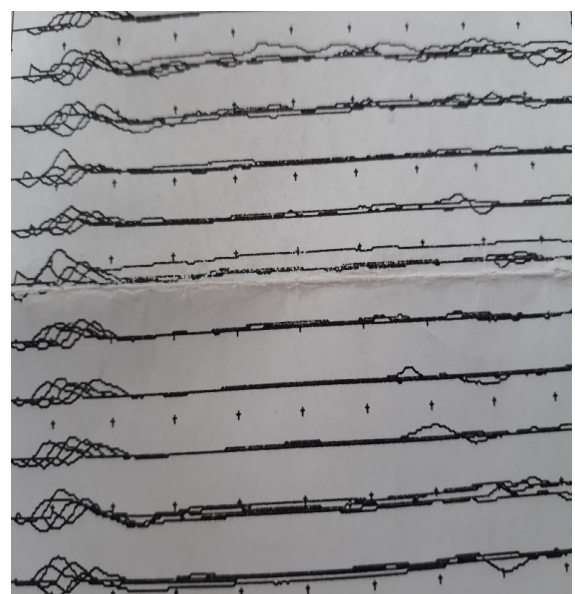

(b)

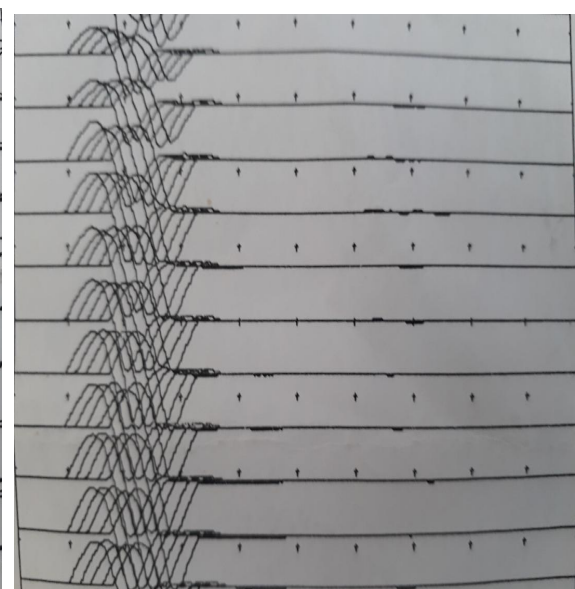

(c)

Figure 1. Results compatible with myasthenia gravis. (a) Large deltoid; (b) Orbicularis of the eyelid; (c) Short abductor of the thumb.

Therapeutically, the B12 vitamintherapy treatment has been followed at the rate of $1000 \mathrm{UI} /$ month and the administered treatment was the azathioprine, 100 $\mathrm{mg} /$ day associated with a corticotherapy of $10 \mathrm{mg}$ /day that permitted a significant improvement of the symptoms. The treatment of anticholinesterase only had not entailed a favorable evolution of the symptoms. The evolution is until this day stable with a normal performance of daily activities and a receding of more than 2 years of follow-up.

\section{Discussion}

We reported an association of seronegative myasthenia gravis and Biermer's anemia.

The myasthenia is defined as an auto-immune illness concerning the neuromuscular junction and its impact varies between 1.5 and 10 cases for 1 million inhabitants [3] [4]. In $20 \%$ of the cases it is seronegative, characterized by the negativity of the anti-RACH and anti-MUSK Ac of the techniques of routine detection [5]. We did not find any association with seronegative myasthenia and Biermer's disease in the literature. In our observation, the diagnosis of negative myasthenia has been put on the basis of the myasthenia diagnosis criteria (existence of a muscular weakness fluctuating spontaneously or under the effect of the effort, associated with a clear answer to a the test of the anticholinesterase of fast action, either to electrophysiolocal signs of post-synaptic block [6] [7]. associated to the negativity of the anti-MUSK antibodies and the anti-receptors antibodies of the acetylcholine twice.

The seronegative myasthenia gravis would have a superimposable clinical and epidemiological presentation with immunopositive forms. However in some sets, it has been reported a more advanced age of onset and a less clear feminine predominance. The resemblance on the clinic plan is globally found in the literature even though a subgroup of negative myasthenia presents some predominantes 
oculo-bulbar demonstrations [8].

The patient was relatively young and presented a generalized shape. The seriousness of the myasthenia is globally similar be the myasthenia is positive or negatives [9].

The myasthenia can sometimes associate to other auto-immune illnesses, the thyroids dysfunction remains the first reasons of association with $5 \%$ to $10 \%$ of the cases [10], and the dosage of the TSHus was at a normal rate in our patient. The myasthenia can associate to numerous diseases, the association to Biermer's anemia that can be defined as an auto-immune gastritis at the origin of a B12 vitamins deficiency responsible for a macrocytic anemia and less frequently of neurological demonstrations [11]. The association of Biermer's anemia and myasthenia is very little described and we did not find an association of seronegative myasthenia gravis and Biermer's anemia in the literature. Some sets in the literature valued the association and described it without specifying the immunological characters of Biermer's anemia [12]. However isolated cases of associations exist. In Goulon et al.'s set [2], as well as Fraissse et al. [13], it has been respectively noted proportions of 3/84 patients having developed some antibodies against-intrinsic factors and no patient developed an authentic Biermer's anemia and 2/45. The Biermer's precedes most often myasthenia [13], which was the case of our patient. In a context Biermer anemia, as in our observation the intervening of a fatigability to the effort associated to a ptosis must evoke an association to Myasthenia.

The negativity of the antibodies doesn't exclude the diagnosis. This negativity would be due to an imperfect sensitivity of the usual techniques of antibodies against-AChR and MuSK tests and/or the controlled presence of antibodies aimed at unidentified antigenic targets [5].

Therapeutically, we noted a good regression of the symptomatology of the $\mathrm{Bi}$ ermer anemia under B12 vitamin therapy alone even though some authors reported a use of the corticotherapy for an improvement of hematological manifestations [14]. As for the myasthenia it has not only been improved under azathioprine associated to the corticotherapy after an absence of improvement under corticotherapy alone, which was in accordance with the therapeutic algorithm of myasthenia.

\section{Conclusion}

The seronegative myasthenia-Biermer's anemia association has not been described in literature. The seronegative character of myasthenia doesn't exclude its association to other auto-immune diseases.

\section{References}

[1] Andrès, E., Renaux, V., Campos, F., et al. (2001) Isolated Neurologic Disorders Disclosing Biermer's Disease in Young Subjects. Revue de Médecine Interne, 22, 389-393. https://doi.org/10.1016/S0248-8663(01)00352-6 
[2] Goulon, M., Zittoun, J., Tuliez, M. and Estournet, B. (1979) Myasthenia and Pernicious Anemia. Revue Neurologique, 135, 605-614.

[3] Vincent, A., Palace, J. and Hilton Jones, D. (2001) Myasthénia gravis. Lancet, 357, 2122-2128. https://doi.org/10.1016/S0140-6736(00)05186-2

[4] Fleury, M.C. and Tranchant, C. (2008) Myastenia Gravis. Revue du Praticien, 58, 2217-2224.

[5] Hong, Y., et al. (2017) Multiple Antibody Detection in 'Seronegative' Myasthenia Gravis Patients. European Journal of Neurology, 24, 844-850.

https://doi.org/10.1111/ene.13300

[6] Evoli, A., Batocchi, A.P., Lo Monaco, M., et al. (1996) Clinical Heterogeneity of Seronegative Myasthenia Gravis. Neuromuscular Disorders, 6, 155-161. https://doi.org/10.1016/0960-8966(96)00009-0

[7] Oosterhuis, H.J.G.H. (1984) Myasthenia Gravis. Clinical Neurology and Neurosurgery Monographs (vol 5). Churchill Livingstone, London.

[8] Birmans, B., Brenner, T., Abramsky, O. and Steiner, I. (1991) Seronegative Myasthenia Gravis: Clinical Features, Reponse to Therapy and Synthesis of Acethylcholine Receptor Antibodies In Vitro. Annals of Neurology, 47, 504-510. https://doi.org/10.1016/0022-510X(91)90067-H

[9] Soliven, B.C., Lange, D.J., Pen, A.S., et al. (1988) Seronegative Myasthenia Gravis. Neurology, 38, 514-518. https://doi.org/10.1212/WNL.38.4.514

[10] Eymard, B. (2014) Myasthenia, from the Internist's Point of View. The Internal Medicine Journal, 35, 421-429.

[11] Simpson, J.A. (1960) Myasthenia Gravis: New Hypothesis. Scottish Medical Journal, 5, 419-439. https://doi.org/10.1177/003693306000501001

[12] Howard, F.M., Silvertein, M.N. and Mulder, D.W. (1965) The Coexistence of Myasthenia Gravis and Pernicious Anemia. The American Journal of the Medical Sciences, 250, 518-526. https://doi.org/10.1097/00000441-196511000-00005

[13] Fraisse, T., Labauge, P., Comu, W., Arlaud, P. and De Waziere, B. (2007) Myasthénie du sujet âgé: Diagnostic, comorbidités et évolution. Presse Medicale, 36, 9-14. https://doi.org/10.1016/j.lpm.2006.07.003

[14] Chang, K.H., Lyu, R.K., Ro, L.S., Wu, Y.R. and Chen, C.M. (2006) Coexistence of Pernicious Anemia and Myasthenia Gravis. A Rare Combination of Auto-Immune Diseases in Taiwan. Journal of the Formosan Medical Association, 105, 946-949. https://doi.org/10.1016/S0929-6646(09)60181-9 